This is an author produced version of a paper published in Remote Sensing Letters.

This paper has been peer-reviewed and is proof-corrected, but does not include the journal pagination.

Citation for the published paper:

Mattias Nyström, Johan Holmgren \& Håkan Olsson. (2013) Change detection of mountain birch using multi-temporal ALS point clouds. Remote Sensing Letters. Volume: 4, Number: 2, pp 190-199. http://dx.doi.org/10.1080/2150704X.2012.714087.

Access to the published version may require journal subscription. Published with permission from: Taylor \& Francis.

Standard set statement from the publisher:

This is an Author's Accepted Manuscript of an article published in REMOTE SENSING LETTERS, 28 Aug 2012, copyright Taylor \& Francis, available online at: http://www.tandfonline.com/doi/full/10.1080/2150704X.2012.714087.

Epsilon Open Archive http://epsilon.slu.se 


\title{
Change detection of mountain birch using multi-temporal ALS point clouds
}

\author{
Mattias Nyström*†, Johan Holmgren† and Håkan Olsson† \\ $\dagger$ Swedish University of Agricultural Sciences, Department of Forest Resource Management, \\ SE-90183 Umeå, Sweden \\ * Corresponding author. E-mail: mattias.nystrom@slu.se
}

Published 2012 in Remote Sensing Letters 4(2), 190-199

\begin{abstract}
The use of multi-temporal laser scanner data is potentially an efficient method for monitoring of vegetation changes, for example at the alpine tree line. Methods for relative calibration of multitemporal ALS data sets and detection of experimental changes of tree cover in the forest-tundra ecotone was tested in northern Sweden $\left(68^{\circ} 20^{\prime} \mathrm{N}, 19^{\circ} 01^{\prime} \mathrm{E}\right)$. Trees were either partly or totally removed on six $\mathrm{m}$ radius sample plots to simulate two classes of biomass change. Histogram matching was successfully used to calibrate the laser metrics from the two data sets and sample plots were then classified into three change classes. The proportion of vegetation returns from the canopy was the most important explanatory variable which provided an overall accuracy of $88 \%$. The classification accuracy was clearly dependent on the density of the forest.
\end{abstract}

\section{Introduction}

The ongoing climate change has led to an increased interest in monitoring potential changes in the foresttundra ecotone. In addition to climate change, insect damage, browsing pressure by herbivores as well as anthropogenic impacts will contribute to changes in the sub-arctic forest-tundra ecotone. These changes are difficult to monitor with manual methods because of the complex mosaic pattern of the ecotone.

Airborne laser scanning (ALS) can efficiently be used to estimate tree height, biomass, and canopy closure in the forest-tundra ecotone (Nyström et al. 2012). In the future, series of ALS data might become available, such multi-temporal datasets will however likely be collected with various resolutions, scanning systems, system parameters, etc. Therefore, research is needed to find methods for efficient calibration and change detection of multi-temporal ALS data.

However, so far there is limited research on using multi-temporal ALS data to detect forest growth or areas with changes in the tree cover. Hyyppä et al. (2003) and $\mathrm{Yu}$ et al. (2004, 2006, 2008) used high resolution ALS data on a single tree level to estimate forest growth and detect harvested trees. St-Onge and Vepakomma (2004) used ALS data acquired five years apart to detect fallen trees and tree growth. Næsset and Gobakken (2005) estimated forest growth in a boreal forest by comparing two independent predictions based on ALS data sets that were acquired two years apart. Solberg et al. (2006) mapped changes in leaf area index (LAI) due to insect attacks by calibration of ALS data to field measurements. Hopkinson et al. (2008) found that higher precision for growth estimation could be achieved with longer time intervals (five years compared to one year). Vastaranta et al. (2011) detected snow-damaged trees at a test site in southern Finland using the difference in ALS measured canopy heights. Næsset (2009) conclude that different ALS sensors, flying altitudes and pulse repetition frequencies affect height-related as well as canopy density-related metrics. Relative calibration methods have earlier been developed for analysis of optical satellite image data (Olsson 1993; Coppin et al. 2004). It is of interest to evaluate if these calibration methods are suitable also for analysis of ALS data.

In this study, two ALS acquisitions were used from two time points with different scanning systems, system parameters, point densities, and flying altitudes. Between the two acquisitions, sample plots were placed out and a proportion of the trees were cut to simulate change. Laser data from 2008 was used as "after" and laser data from 2010 as "before" to simulate afforestation. The objectives were to (1) validate the effect of a histogram matching algorithm when comparing the two data sets, and to (2) identify metrics from ALS data that are efficient for detecting changes of vegetation in the sub-alpine tree line ecotone using supervised classification.

\section{Material and methods}

\subsection{Study area}

The study area is about two $\mathrm{km} 2$ and located six $\mathrm{km}$ southeast of Abisko in northern Sweden, centred on Lat. N 68'20', Long. E $19^{\circ} 01$ ' (figure 1(a)). The dominating specie is mountain birch (Betula pubescens ssp. czerepanovii), but some junipers (Juniperus 
communis), rowans (Sorbus aucuparia), and willows (Salix spp.) taller than $1.5 \mathrm{~m}$ are also present. The birches in the study area are of the multi-stem type with several stems often sharing the same root system (polymorphism). Sample plots were placed in the ecotone between birch forest and tundra (denoted forest-tundra ecotone). This ecotone was characterized by a mosaic pattern of forest and alpine heath vegetation, with elevations from $410-670 \mathrm{~m}$ a.s.l.

[Figure 1]

\subsection{Laser data acquisitions}

Laser data were acquired under leaf-on conditions at two occasions with different laser scanners (table 1). The first scanning was done in 2008 with a TopEye MkII (denoted TopEye) mounted on a helicopter and the second scanning was done in 2010 with an Optech ALTM Gemini (denoted Optech), mounted within a fixed-wing aircraft. In both cases, scanning was performed with the flying direction orthogonal to the main slope.

[Table 1]

\subsection{Field data}

The field inventory was carried out between the two laser data acquisitions, during two weeks in June 2010 (43 sample plots, table 2). The 43 sample plots had six $\mathrm{m}$ radius and were subjectively selected to match the following criteria: (1) $90 \%$ of the trees in the range 1.5 $2.5 \mathrm{~m}$ tall, (2) no trees taller than $3.5 \mathrm{~m}$, and (3) no dominating bush layer (0-1.5 m) on the sample plot. In addition, 53 sample plots, inventoried in August 2009 and June 2010, from a previous study in the area (Nyström et al. 2012) were used. These 53 existing sample plots had ten $\mathrm{m}$ radius and included some trees taller than $3.5 \mathrm{~m}$. Only six $\mathrm{m}$ radius of the existing sample plots were used in the analysis and the sample plots were revisited in 2010 to assure they were unchanged. The centre position of all sample plots was measured with sub-decimeter accuracy. Figure 1(b) show one of the sample plots from the field data collection in 2010.

Each sample plot was then assigned one of the following treatments, in order to simulate different change classes: (1) reference, no removal of trees, (2) removal of $50 \%$ of the trees taller than $1.5 \mathrm{~m}$, and (3) removal of $100 \%$ of the trees taller than $1.5 \mathrm{~m}$. Spatial location and height distribution of removed trees were as evenly distributed as possible on each sample plot. The treatment was extended to seven $\mathrm{m}$ radius to minimize problems with horizontal dislocation between field and laser data, but still only six m radius was used when extracting laser data.

\section{[Table 2]}

\subsection{Laser data processing}

TerraScan (Soinen 2010) was used to classify the point cloud into ground and non-ground in the same way as Nyström et al. (2012). The statistical software R (R Development Core Team, 2011) and in house developed programs were used to further process the ALS point cloud. No removal of overlapping data from different flight lines was done in either data set.

A digital elevation model (DEM) with $0.5 \mathrm{~m}$ raster cell size representing the ground level was created for each data set. First, the mean elevation of ground classified points was calculated for each cell. Secondly, empty cells were assigned elevation values by triangular irregular network (TIN) interpolating the filled cells. Canopy heights $(\mathrm{CH})$ were calculated by subtracting the DEM from the $z$-value (height) of each laser return. A digital surface model (DSM) with $0.5 \mathrm{~m}$ raster cell size was created by assigning each grid cell the maximum $z$-value for laser returns classified as non-ground. A normalized DSM (nDSM) was calculated by subtracting the DEM from the DSM. All data points above $15 \mathrm{~m}$ were omitted in $\mathrm{CH}$ and $\mathrm{nDSM}$ to avoid false reflections (the $15 \mathrm{~m}$ limit was chosen given that no trees taller than $10.5 \mathrm{~m}$ were found in the area).

A height threshold (Nilsson 1996) of $0.7 \mathrm{~m}$ was used when calculating metrics from the ALS point cloud above ground ( $\mathrm{CH}$ and nDSM). The threshold was chosen to obtain reliable laser metrics for sample plots with trees around $1.5 \mathrm{~m}$ tall in the same time as most of the shrub vegetation close to the ground was omitted.

All the following laser metrics were created from both nDSM and CH. Height percentiles $\left(\mathrm{H}_{20}, \mathrm{H}_{40}\right.$, ..., $\left.H_{100}\right)$ in steps of 20 were calculated using height values above the threshold. In addition, height percentiles were also calculated for $H_{95}$ and $H_{99}$ since these are strong indicators of the height of vegetation. Ten vertical canopy density metrics $\left(D_{0}\right.$, $D_{1}, \ldots, D_{9}$ ) were estimated in accordance to e.g. Næsset and Gobakken (2008) using the height threshold as the lower limit and $H_{95}$ as the upper limit. A sum of squared canopy heights $\left(H_{\text {sum }}\right)$ was calculated by taking the sum of squared canopy heights divided by the number of canopy height measurements above the height threshold (Nyström et al. 2012). Vegetation ratio (VR) was calculated both by dividing the number of laser returns above the height threshold with the total number of returns inside the sample plot and alternatively by using a point-weighted approach (denoted $\mathrm{VR}^{\mathrm{pw}}$ ) according to Nyström et al. (2012) using a radius of $0.59 \mathrm{~m}$ for TopEye and $1.00 \mathrm{~m}$ for 
Optech, where the radii are the same as in Nyström et al. (2012). The returns used to calculate the vegetation ratio was either all returns (denoted $\mathrm{VR}_{\text {all }}$ ) or only first returns (denoted $\mathrm{VR}_{1}$ st). Metrics calculated from nDSM are denote e.g. $H_{20}^{\mathrm{nDSM}}$ and metrics calculated from $\mathrm{CH}$ are denoted e.g. $H_{20}^{\mathrm{CH}}$.

\subsection{Histogram matching}

An area of $1.8 \mathrm{~km} 2$ (figure 1(a)) was used to calculate laser metrics for $10 \mathrm{~m} \times 10 \mathrm{~m}$ pixels. The size of the pixels was chosen to match the area of the sample plots used in the change detection experiment. Histogram matching was used to calibrate the metrics from the two laser data acquisitions to a common distribution. Cumulative histograms were created for each laser metric in the two data sets using 100 bins with minimum and maximum values from each laser metric as bounds. In the histogram matching process, the values were interpolated between the bins using piecewise cubic hermite interpolation (Fritsch and Carlson 1980). The histograms from the Optech laser metrics were matched to the histograms from the TopEye laser metrics. In total 18450 pixels were inside the bounding box (figure 1(a)), but several pixels had no laser metrics because no vegetation above the height threshold $(0.7 \mathrm{~m})$ was present. Therefore only 10593 pixels were used to create the histograms.

To simulate afforestation, the first laser data collection (2008) was used as "after" and the second laser data collection (2010) as "before". The field reference plots were used to evaluate the similarity of the laser metrics after histogram matching was conducted. The reference plots had no unusual changes according to the field survey. The measures used were relative RMSE (RMSE ${ }_{\mathrm{r}}$ ) and relative BIAS( BIAS $_{\mathrm{r}}$ ) calculated from the unchanged reference sample plots $(i)$ :

$$
\begin{aligned}
\operatorname{RMSE}_{\mathrm{r}}(k) & =\frac{\sqrt{\sum_{i=1}^{n}\left(T_{1}(i, k)-T_{2}(i, k)\right)^{2} / n}}{\bar{T}_{1,2}(k)} \\
\operatorname{BIAS}_{\mathrm{r}}(k) & =\frac{\sum_{i=1}^{n}\left(T_{1}(i, k)-T_{2}(i, k)\right)}{n \bar{T}_{1,2}(k)}
\end{aligned}
$$

where $T_{1}(i, k)$ is laser metric $k$ of sample plot $i$ from the TopEye data and $T_{2}(i, k)$ is the same laser metric $(k)$ from the same sample plot $(i)$ in the Optech data, $n$ is the number of observations, and $\bar{T}_{1,2}(k)$ is the mean value of laser metric $k$, i.e. mean value of $T_{1}(k)$ and $T_{2}(k)$.

\subsection{Classification}

The sample plots were classified into the three change classes using Linear Discriminant Analysis (LDA) in order to check which laser metrics that best discriminated experimentally changed from unchanged vegetation. The MASS-package (Venables and Ripley, 2002) in the statistical software R (R Development Core Team, 2011) was used for the classification. Prior probabilities were set to $1 / 3$ for each of the three classes. The relative difference (equation (3)) of the laser metrics was used as explanatory variables.

$\Delta(i, k)=\frac{T_{1}(i, k)-T_{2}(i, k)}{T_{1}(i, k)+T_{2}(i, k)+10^{-15}}$
A small number $\left(10^{-15}\right)$ was added in the denominator to avoid division by zero. The classification was based on either one or a combination of two explanatory variables $(\Delta(i, k))$. Leave-oneout cross-validation was used to calculate classification accuracy using all 96 sample plots.

To evaluate the classification based on laser metrics, sample plots were divided into three change classes, which also were stratified into three density categories depending on the total number of trees taller than 1.5 m (Table 2).

\section{Results}

Each laser metric from the second scanning (Optech) was histogram matched to the histogram from the first scanning (TopEye). The cumulative histograms created for the $95^{\text {th }}$ height percentile $\left(H_{95}^{\mathrm{nDSM}}\right)$ and the vegetation ratio ( $\mathrm{VR}_{\text {all }}^{\mathrm{nDSM}}$ ) from $\mathrm{nDSM}$ is shown in figure 2. Figure 3 shows one-to-one plots of the $95^{\text {th }}$ height percentile and the vegetation ratio without calibration and calibrated using histogram matching. In the figure it can be seen that after histogram matching was applied, the relationship between the metrics from the different sensors is no longer curved. 


\section{[Figure 2] [Figure 3]}

The similarity of laser metrics between the two ALS acquisitions was evaluated by calculating RMSE $_{\mathrm{r}}$ and BIAS $_{\mathrm{r}}$ for the reference sample plots with and without histogram matching applied. In table 3 it can be seen that laser metrics calculated from nDSM tend to have lower $\mathrm{RMSE}_{\mathrm{r}}$ and $\mathrm{BIAS}_{\mathrm{r}}$ than metrics calculated using $\mathrm{CH}$. BIAS ras always a low value when histogram matching was applied.

[Table 3]

When using only one explanatory variable for classification of the experimental changes, laser metrics based on the density of the vegetation provided generally higher overall classification accuracy (Table $4)$. There was only $1 \%$ higher classification accuracy when the best combination of two metrics, height density $1\left(D_{1}^{\mathrm{nDSM}}\right)$ and the $95^{\text {th }}$ height percentile ( $H_{95}^{\mathrm{CH}}$ ), was used. Table 5 shows the error matrices for a height percentile $\left(H_{95}^{\mathrm{nDSM}}\right)$, a density metric ( $D_{1}^{\mathrm{nDSM}}$ ) and a combination of a height percentile and a density metric $\left(H_{95}^{\mathrm{CH}}\right.$ and $\left.D_{1}^{\mathrm{nDSM}}\right)$. Almost none of the $50 \%$ changed sample plots were correctly classified using only a height percentiles. Considerably higher classification accuracy for the $50 \%$ changed sample plots was achieved using only a measure of density.

[Table 4] [Table 5]

\section{Discussion}

This is to our knowledge the first study that reports the performance of histogram matching for multi-temporal relative calibration of ALS data. The cumulative histograms (figure 2(b)) created for the vegetation ratio $\left(\mathrm{VR}_{\text {all }}^{\mathrm{nDSM}}\right)$ were found to be almost identical after the histogram matching was applied. Consequently, the calibrated data became also better aligned to the oneto-one line (figure $3(c-d)$ ).

$\mathrm{RMSE}_{\mathrm{r}}$ and $\mathrm{BIAS}_{\mathrm{r}}$ (table 3) were calculated using the 68 reference sample plots without experimental changes to evaluate similarity between the two data sets. The height percentiles had considerably lower $\mathrm{RMSE}_{\mathrm{r}}$ than the density metrics. Bater et al. (2011) compared four acquisitions from the same day and also noted that the height percentiles were more stable than density metrics. A possible reason is that the height percentiles are less sensitive for view angle effects (Holmgren et al. 2003).

BIAS $_{r}$ has always a low value when histogram matching is used. When calculating BIAS $_{\mathrm{r}}$ using only the sample plots from the taller forest (previously inventoried sample plots), BIAS $_{\mathrm{r}}$ has a value very close to zero for all metrics. This indicates that some of the change in the reference plots with lower forest might be due to forest growth, but can also be due to difficulties to measure low forest with ALS.

The laser metrics created using nDSM values have lower $\mathrm{RMSE}_{\mathrm{r}}$ for the reference plots and provide higher classification accuracy than metrics created from $\mathrm{CH}$. Multi-temporal data requires measures to be spatially normalized at each time point to avoid problems with uneven distribution of laser points (Nyström et al. 2012). There is a need for further research on spatial normalization methods when analysing multi-temporal data.

The reason for the low classification accuracy using only a height percentile can be that trees taller than 1.5 $\mathrm{m}$ still remained on the sample plots. The highest classification accuracy was achieved using a density metric $\left(D_{1}^{\mathrm{nDSM}}\right)$. Divided into the three density classes, classification accuracy was $71 \%, 81 \%$ and $95 \%$ in low-, medium- and high density forest, respectively. Hence, classification also seems to be dependent on the tree density.

High classification accuracy (88\%) was achieved using a measure of vegetation density derived from data acquired at two time points with different sensors, flying altitude and scanning pattern. This was obtained by using metrics corrected for uneven distribution of laser points. Histogram matching reduced the difference between the two data sets for most metrics and is likely to be a straight forward way to produce change imagery from multi-temporal ALS data sets. The use of accurately calibrated change imagery is however only a transformation of the available data and will thus not necessarily improve the outcome of computer based classifications of the changes.

\section{Acknowledgements}

This study is part of the research programme Environmental Mapping and Monitoring with Airborne laser and digital images (EMMA), financed by the Swedish Environmental Protection Agency. The laser data sets were acquired through cooperation with the University of Lund and the new national elevation model project $(\mathrm{NNH})$ at the Swedish National Land Survey. The Abisko Scientific Research Station is acknowledged for supporting the work with field data acquisition.

\section{References}

BATER, C.W., WULDER, M.A., COOPS, N.C., NELSON, R.F., HILKER, T. and NÆSSET, E., 2011, Stability of Sample-Based Scanning-LiDAR-Derived Vegetation Metrics for Forest Monitoring. IEEE Transactions on Geoscience and Remote Sensing, , 49, pp. 2385-2392. 
COPPIN, P., JONCKHEERE, I., NACKAERTS, K., MUYS, B. and LAMBIN, E., 2004, Digital change detection methods in ecosystem monitoring: a review. International Journal of Remote Sensing, 25, pp. 1565-1596.

FRITSCH, F.N. and CARLSON, R.E., 1980, Monotone Piecewise Cubic Interpolation. Siam Journal on Numerical Analysis, 17, pp. 238-246.

HOLMGREN, J., NILSSON, M., and OLSSON, H, 2003, Simulating the effect of LIDAR scanning angle for estimation of mean tree height and canopy closure. Canadian Journal of Remote Sensing, 29, pp. 623-632.

HOPKINSON, C., CHASMER, L. and HALL, R.J., 2008, The uncertainty in conifer plantation growth prediction from multi-temporal lidar datasets. Remote Sensing of Environment, 112, pp. 1168-1180.

HYYPPÄ, J., XIAOWEI, Y., RÖNNHOLM, P., KAARTINEN, H. and H, H., 2003, Factors Affecting Object-Oriented Forest Growth Estimates Obtained Using Laser Scanning. The photogrammetric journal of Finland, 18, pp. 16-31.

NÆSSET, E., 2009, Effects of different sensors, flying altitudes, and pulse repetition frequencies on forest canopy metrics and biophysical stand properties derived from small-footprint airborne laser data. Remote Sensing of Environment, 113, pp. 148-159.

NÆSSET, E. and GOBAKKEN, T., 2005, Estimating forest growth using canopy metrics derived from airborne laser scanner data. Remote Sensing of Environment, 96, pp. 453-465.

NÆSSET, E. and GOBAKKEN, T., 2008, Estimation of above- and below-ground biomass across regions of the boreal forest zone using airborne laser. Remote Sensing of Environment, 112, pp. 3079-3090.

NILSSON, M., 1996, Estimation of tree weights and stand volume using an airborne lidar system. Remote Sensing of Environment, 56, pp. 1-7.

NYSTRÖM, M., HOLMGREN, J. and OLSSON, H., 2012, Prediction of tree biomass in the forest-tundra ecotone using airborne laser scanning. Remote Sensing of Environment, 123, pp. 271-279.

OLSSON, H., 1993. Regression functions for multitemporal relative calibration of Thematic Mapper data over boreal forests. Remote Sensing of Environment, 46, pp. 89-102.
R DEVELOPMENT CORE TEAM, 2011, R: A language and environment for statistical computing, (Vienna: R Foundation for Statistical Computing).

SOININEN, A., 2010, TerraScan User's Guide. Available online at: www.terrasolid.fi (accessed 31 July 2010).

SOLBERG, S., NÆSSET, E., HANSSEN, K.H. and CHRISTIANSEN, E., 2006, Mapping defoliation during a severe insect attack on Scots pine using airborne laser scanning. Remote Sensing of Environment, 102, pp. 364376.

ST-ONGE, B. and VEPAKOMMA, U., 2004, Assessing Forest Gap Dynamics and Growth Using Multi-Temporal Laser-Scanner Data. In International Archieves of Photogrammetry, Remote Sensing and Spatial Information Sciences XXXVI 8/W2, 3-6 October 2004, M. Thies, B. Koch, H. Spiecker and H. Weinacker (Eds.), Freiburg, Germany, pp. 173-178. Available online at: http://www.isprs.org/proceedings/XXXVI/8-W2/

VASTARANTA, M., KORPELA, I., UOTILA, A., HOVI, A. and HOLOPAINEN, M., 2011, Mapping of snowdamaged trees based on bitemporal airborne LiDAR data. European Journal of Forest Research, 131, pp. 1-12.

VENABLES, W. N. AND RIPLEY, B. D., 2002. Modern Applied Statistics with S, (New York: Springer).

YU, X., HYYPPÄ, J., KAARTINEN, H., MALTAMO, M. and HYYPPÄ, H., 2008, Obtaining plotwise mean height and volume growth in boreal forests using multi-temporal laser surveys and various change detection techniques. International Journal of Remote Sensing, 29, pp. 13671386.

YU, X.W., HYYPPÄ, J., KAARTINEN, H. and MALTAMO, M., 2004, Automatic detection of harvested trees and determination of forest growth using airborne laser scanning. Remote Sensing of Environment, 90, pp. 451-462.

YU, X.W., HYYPPÄ, J., KUKKO, A., MALTAMO, M. and KAARTINEN, H., 2006, Change detection techniques for canopy height growth measurements using airborne laser scanner data. Photogrammetric Engineering and Remote Sensing, 72, pp. 1339-1348. 

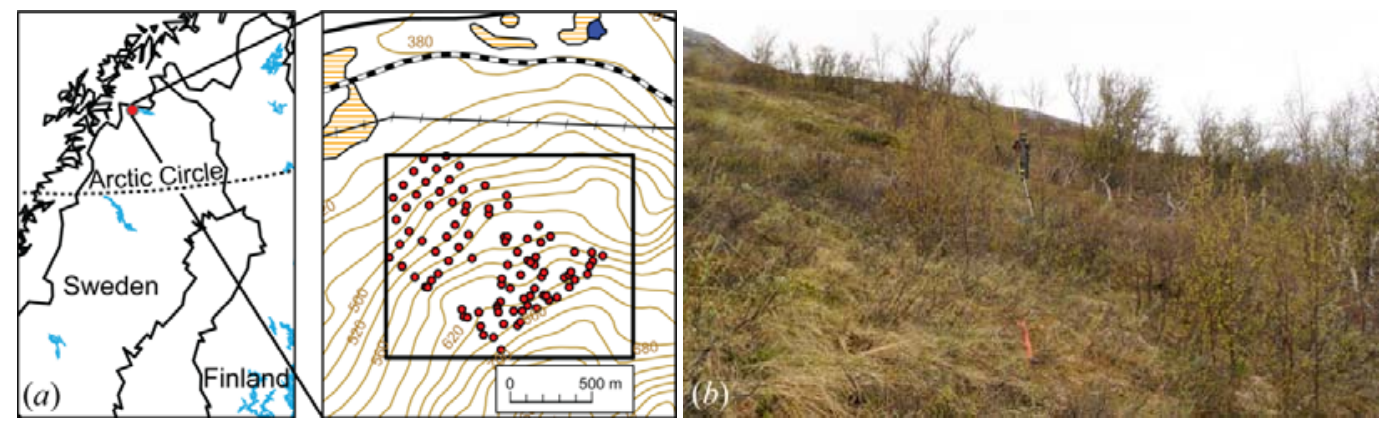

Figure 1. (a) The study area in northern Sweden. The red dots in the enlarged map are the sample plots and the black polygon is the area used to create cumulative histograms for histogram matching. (c) Lantmäteriet, I 2010/0345. (b) One of the sample plots from the field data collection. This sample plot was classified to have medium tree density. The red/yellow measuring pole is $3 \mathrm{~m}$ in length.
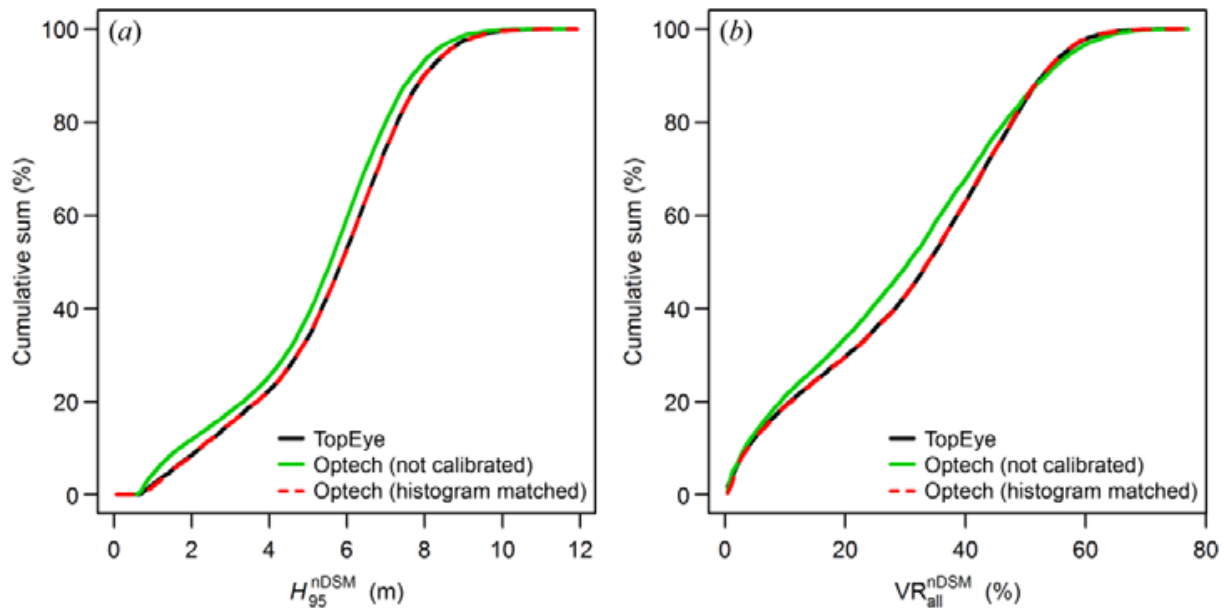

Figure 2. The red dashed line is the cumulative histogram of Optech after histogram matching was applied to match the histogram of TopEye (black line). (a) $95^{\text {th }}$ height percentile $\left(H_{95}^{\mathrm{nDSM}}\right)$. (b) Vegetation ratio $\left(\mathrm{VR}_{\text {all }}^{\mathrm{nDSM}}\right)$.
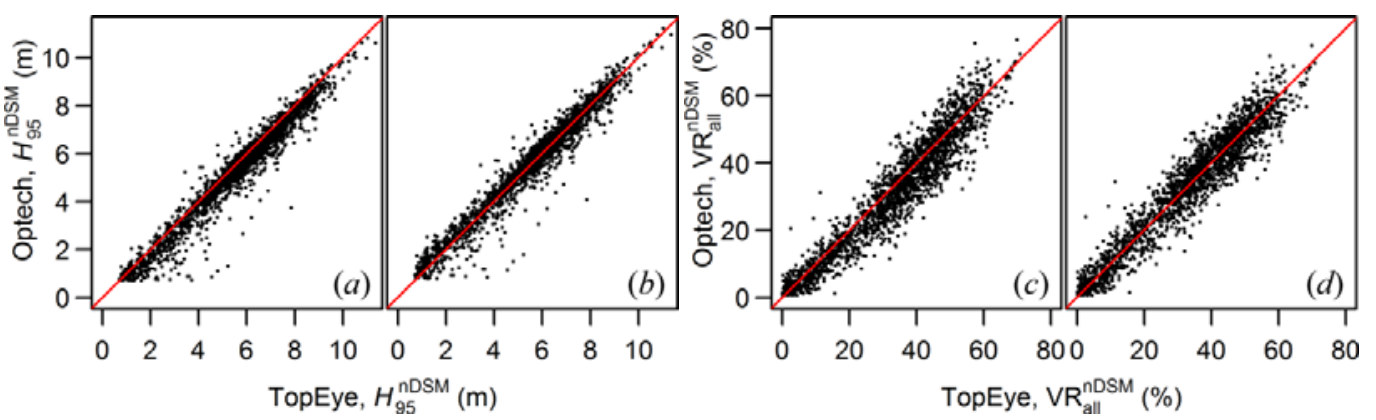

Figure 3. One-to-one plot before and after histogram matching was applied. The red line is the one-to-one line. Only every fifth point is plotted. (a) not calibrated $95^{\text {th }}$ height percentile $\left(H_{95}^{\mathrm{nDSM}}\right),(b)$ histogram matched $H_{95}^{\mathrm{nDSM}}$, (c) not calibrated vegetation ratio $\left(\mathrm{VR}_{\mathrm{all}}^{\mathrm{nDSM}}\right)$ and $(d)$ histogram matched $\mathrm{VR}_{\mathrm{all}}^{\mathrm{nDSM}}$. 
Table 1. Summary of the laser scanner properties and flight parameters of the two laser data acquisitions.

\begin{tabular}{|c|c|c|}
\hline Parameter & TopEye MkII & Optech ALTM Gemini \\
\hline Scanning date & Aug. 1, 2008 & Aug. 20, 2010 \\
\hline Flight altitude (m above ground) & 500 & 1740 \\
\hline Footprint (m) & 0.5 & 0.5 \\
\hline Pulse repetition frequency $(\mathrm{kHz})$ & 50 & 70 \\
\hline Scan frequency $(\mathrm{Hz})$ & 35 & 37 \\
\hline Wave length (nm) & 1064 & 1064 \\
\hline Pulse length (ns) & $4(1.2 \mathrm{~m})$ & $6.8(2.0 \mathrm{~m})$ \\
\hline Scan type & Palmer & Oscillating mirror \\
\hline Scan width (across flight dir., deg.) & \pm 20 & \pm 20 \\
\hline Scan width (along flight dir., deg.) & \pm 14 & 0 \\
\hline Points extracted per pulse & $\leq 2$ & $\leq 4$ \\
\hline Minimum point density ${ }^{\dagger}\left(\mathrm{m}^{-2}\right)$ & 3.0 & 0.7 \\
\hline Average point density ${ }^{\dagger}\left(\mathrm{m}^{-2}\right)$ & 12.0 & 1.2 \\
\hline Maximum point density ${ }^{\dagger}\left(\mathrm{m}^{-2}\right)$ & 34.8 & 2.4 \\
\hline
\end{tabular}

Based on the 96 sample plots used in this article.

Table 2: Number of field sample plots in each change class (reference (unchanged), 50\% and $100 \%$ of trees removed) and divided into the tree density classes (low, medium and high density).

\begin{tabular}{lccc}
\hline & \multicolumn{3}{c}{ Tree density class (trees per sample plot) } \\
\cline { 2 - 4 } Change class $^{\dagger}$ & Low (5-10) & Medium (11-50) & High (51-100) \\
\hline Reference & 11 & 22 & 35 \\
$50 \%$ & 5 & 4 & 4 \\
$100 \%$ & 6 & 5 & 4 \\
\hline \multicolumn{4}{c}{${ }^{\dagger}$ Amount of stems removed from each sample plot. }
\end{tabular}

Table 3. $\mathrm{RMSE}_{\mathrm{r}}$ and $\mathrm{BIAS}_{\mathrm{r}}$ for the 68 reference sample plots. In each of the following categories $D^{\mathrm{CH}}, D^{\mathrm{nDSM}}, H^{\mathrm{CH}}$, and $H^{\mathrm{nDSM}}$, only the metric with lowest $\mathrm{RMSE}_{\mathrm{r}}$ after histogram matching is presented. The notations of the laser metrics are defined in section 2.4.

\begin{tabular}{|c|c|c|c|c|}
\hline \multirow[b]{2}{*}{ Laser metric } & \multicolumn{2}{|c|}{$\mathrm{RMSE}_{\mathrm{r}}(\%)$} & \multicolumn{2}{|c|}{$\mathrm{BIAS}_{\mathrm{r}}(\%)$} \\
\hline & $\begin{array}{c}\text { Not } \\
\text { calibrated }\end{array}$ & $\begin{array}{l}\text { Histogram } \\
\text { matched }\end{array}$ & $\begin{array}{c}\text { Not } \\
\text { calibrated }\end{array}$ & $\begin{array}{c}\text { Histogram } \\
\text { matched }\end{array}$ \\
\hline$H_{95}^{\mathrm{nDSM}}$ & 9.2 & 6.0 & 6.8 & -0.4 \\
\hline$H_{95}^{\mathrm{CH}}$ & 8.5 & 6.7 & 4.5 & -0.2 \\
\hline$H_{\text {sum }}^{\mathrm{nDSM}}$ & 14.5 & 11.5 & 6.8 & -1.2 \\
\hline$H_{\text {sum }}^{\mathrm{CH}}$ & 13.6 & 13.7 & -0.6 & -1.6 \\
\hline$D_{4}^{\mathrm{nDSM}}$ & 15.5 & 14.5 & 2.9 & -0.9 \\
\hline $\mathrm{VR}_{\mathrm{all}}^{\mathrm{nDSM}}$ & 17.6 & 15.2 & 5.3 & -1.9 \\
\hline $\mathrm{VR}_{\mathrm{all}}^{\mathrm{pw}, \mathrm{CH}}$ & 18.1 & 16.4 & -1.2 & -1.8 \\
\hline $\mathrm{VR}_{1 s \mathrm{t}}^{\mathrm{pw}, \mathrm{CH}}$ & 23.4 & 16.5 & 12.0 & -2.4 \\
\hline$D_{0}^{\mathrm{CH}}$ & 22.4 & 19.4 & 5.0 & -2.3 \\
\hline $\mathrm{VR}_{\mathrm{all}}^{\mathrm{CH}}$ & 22.4 & 19.4 & 5.0 & -2.3 \\
\hline $\mathrm{VR}_{1^{\text {st }}}^{\mathrm{CH}}$ & 32.8 & 21.2 & 18.3 & -2.8 \\
\hline Mean: & 18.0 & 14.6 & $6.2^{\dagger}$ & $1.6^{\dagger}$ \\
\hline
\end{tabular}


Table 4. Overall classification accuracy after leave-one-out cross-validation in the three change classes using one laser metric as explanatory variable. In each of the following categories $D^{\mathrm{CH}}, D^{\mathrm{nDSM}}, H^{\mathrm{CH}}$, and $H^{\mathrm{nDSM}}$, only the metric with highest overall classification accuracy is presented.

\begin{tabular}{lcc}
\hline & \multicolumn{2}{c}{ Classification accuracy (\%) } \\
\cline { 2 - 3 } Laser metric & Not calibrated & $\begin{array}{c}\text { Histogram } \\
\text { matched }\end{array}$ \\
\hline$D_{1}^{\mathrm{nDSM}}$ & 86 & 88 \\
$\mathrm{VR}_{\mathrm{all}}^{\mathrm{nDSM}}$ & 86 & 86 \\
$\mathrm{VR}_{1 \mathrm{st}}^{\mathrm{pl}} \mathrm{CH}$ & 82 & 85 \\
$\mathrm{VR}_{\mathrm{all}}^{\mathrm{pw}, \mathrm{CH}}$ & 80 & 84 \\
$\mathrm{VR}_{1 \mathrm{st}}^{\mathrm{CH}}$ & 75 & 83 \\
$D_{0}^{\mathrm{CH}}$ & 79 & 82 \\
$\mathrm{VR}_{\mathrm{all}}^{\mathrm{CH}}$ & 79 & 82 \\
$H_{95}^{\mathrm{nDSM}}$ & 80 & 81 \\
$H_{100}^{\mathrm{CH}}$ & 84 & 80 \\
$H_{\text {sum }}^{\mathrm{nDSM}}$ & 73 & 69 \\
$H_{\mathrm{sum}}^{\mathrm{CH}}$ & 72 & 67 \\
\hline
\end{tabular}

Table 5. Error matrix for leave-one-out cross-validated supervised classification using histogram matched metrics: (1) $H_{95}^{\mathrm{nDSM}}$, (2) $D_{1}^{\mathrm{nDSM}}$ and (3) $H_{95}^{\mathrm{CH}}$ and $D_{1}^{\mathrm{nDSM}}$. The change classes, reference, $50 \%$ and $100 \%$, gives the proportion of tree stems removed on each sample plot.

\begin{tabular}{|c|c|c|c|c|c|c|c|c|c|c|}
\hline & \multicolumn{9}{|c|}{ True } \\
\hline & & \multicolumn{3}{|c|}{$H_{95}^{\mathrm{nDSM}}$} & \multicolumn{3}{|c|}{$D_{1}^{\mathrm{nDSM}}$} & \multicolumn{3}{|c|}{$H_{95}^{\mathrm{CH}}$ and $D_{1}^{\mathrm{nDSM}}$} \\
\hline & & Reference & $50 \%$ & $100 \%$ & Reference & $50 \%$ & $100 \%$ & Reference & $50 \%$ & $100 \%$ \\
\hline \multirow{3}{*}{ 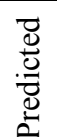 } & Reference & 65 & 8 & 3 & 64 & 3 & 0 & 66 & 3 & 0 \\
\hline & $50 \%$ & 3 & 3 & 2 & 3 & 8 & 3 & 1 & 9 & 5 \\
\hline & $100 \%$ & 0 & 2 & 10 & 1 & 2 & 12 & 1 & 1 & 10 \\
\hline
\end{tabular}

